\title{
Analysis of static and free vibration of the sandwich folded plate using the Layerwise theory
}

- Bui Xuan Thang

University of Science, VNU-HCM

- Dang Trung Hau

Ton Duc Thang University, Ho Chi Minh

(Received on $20^{\text {th }}$ December 2016, accepted on $28^{\text {th }}$ November 2017)

\begin{abstract}
In this paper, the static and free vibration analyses of the sandwich folded plate modeled by layer-wise $(L W)$ theory are studied. In the theory, the continuity displacement condition is imposed at the layer's interfaces. Each layer of the plate is modeled by the first-order shear deformation theory (FSDT). The
\end{abstract}

numerical solutions are obtained by using the cellbased smoothed discrete shear gap method (CS-DSG3). Some examples are implemented to demonstrate the accuracy of the $L W$ theory for the sandwich folded plate analyses.

Keywords: sandwich folded plate, Layer-wise ( $L W)$ theory, a cell-based smoothed discrete shear gap method (CS-DSG3)

\section{INTRODUCTION}

Folded plates are shell types consisting of flat plates, rigidly connected together along their edges forming folds. Thanks to those folds, folded plates have better loading capacity, lighter weight and betterlooking in comparison to flat plates. Sandwich plates fabricated by attaching two thin stiff skins to a thick lightweight core are composite plate types. This structure provide high bending stiffness with overall low density, high noise immunity and high thermal insulation. Hence, sandwich folded plate structures have a wide range of applications such as interiors, roofs, buildings, vehicle chassis, ship hulls and among other structures. However, sandwich structures are very susceptible to failure due to local stress concentrations induced in areas of load introduction, supports, geometrical and material discontinuities. These local

stress concentrations are caused by local bending effects, where the individual face sheets tend to bend about their own middle surface rather than about the middle surface of the sandwich. So study about behavior of this structure is very important.

Some of researches investigating to mechanical behavior of both isotropic and laminated composite folded plates are published. Details can be found in publication L. Le-Anh et al. [1]. Some typical studies can be mentioned as: Goldberg and Leve [2] are regarded as the first to give the exact static solution of folded plates. Based on Vlasov's theory of thin-wall beams, Bar-Yoseph et al. [3] proposed an approximated method for folded plates. Peng et al. [4] used Meshfree method associated with the first-order shear deformation theory (FSDT) to analyze the bending

Trang 214 
behavior of folded plates. N. Nguyen-Minh et al. [5] used a cell-based smoothed discrete shear gap method (CS-DSG3) based on FSDT for static and free vibration of folded plate. Guha Niyogi et al. [6] used a nine-node plate element that incorporated first-order transverse shear deformation and rotary inertia to predict the free and forced vibration response of folded laminated composite plate structures. Haldar and Sheikh [7] used a shear flexible element to analyze the free vibration of both isotropic and composite plates. Peng et al. [8] successfully proposed a mesh-free method based on FSDT for bending analysis of folded laminated plates. All of studies in literature related to the analysis of folded composite plates used the equivalent singlelayer (EQ) theory to model behavior of laminate composite plate. This theory is simple and achieved good results. to date, there have been no studies applying layer-wise (LW) theory to the analysis of sandwich folded plate. In LW theory, the independent degrees of freedom are considered for each layer. So this theory is more suitable for model of sandwich structure whose behavior of each layer is very differente.

In the other front of the development of numerical methods, CS-DSG3 was proposed recently by NguyenThoi et al. [9] for static and free vibration analyses of

$$
\begin{aligned}
& u^{(c)}(x, y, z)=u_{0}(x, y)+z^{(c)} \beta_{y}^{(c)} \\
& v^{(c)}(x, y, z)=v_{0}(x, y)-z^{(c)} \beta_{x}^{(c)} \\
& w^{(c)}(x, y, z)=w_{0}(x, y)
\end{aligned}
$$

where $u_{0}$ and $v_{0}$ denote the in-plane displacements on the mid-plane; $w_{0}$ is the deflection; $\beta_{x}^{(c)}$ and $\beta_{y}^{(c)}$ are the rotations of normal of the middle layer to the middle plane around $x$-axis and $y$-axis. plates. This method have also been further investigated and applied to various problems such as composite plates [10], shell [11], piezo plate [12], plates resting on foundation [13], etc. Obtained results of this method were free of shear locking and achieved the high accuracy compared to the exact solutions and others existing elements. In this study, CS-DSG3 is proposed to combine with LW theory for static and free vibration analyses of sandwich folded plates. Numerical results in this paper show that, LW theory give good results that can't be obtained by EQ theory in comparison with commercial program ANSYS.

\section{LW FORMULATION BASED ON FSDT FOR SANDWICH FOLDED PLATE}

In this paper, the sandwich folded plate in global coordinate system $O X Y Z$ is modeled by the flat shell theory [14], in which each mid-plane element is mapped to a local coordinate system oxyz. The displacement field for the sandwich folded plate using LW theory is based on two assumptions: (1) the analysis of each layer is based on the $\mathrm{C}^{0}$-type first-order shear deformation model and (2) the continuity condition of the displacement is imposed at the layer's interfaces [15]. The displacement field for the core layer is given by [1]. 


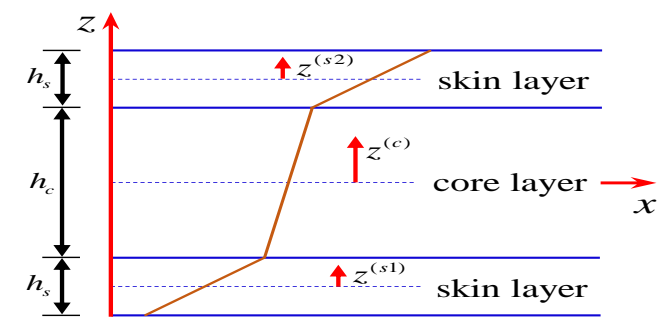

Fig. 1. Layer-wise kinematics of a sandwich plate

The corresponding displacement fields for the skin layers shown in Fig. 1 are given by [2].

$$
\begin{aligned}
& \left\{\begin{array}{l}
u^{(s 1)}(x, y, z)=u_{0}(x, y)-\frac{h_{c}}{2} \beta_{y}^{(c)}-\frac{h_{s}}{2} \beta_{y}^{(s 1)}+z^{(\mathrm{s} 1)} \beta_{y}^{(s 1)} \\
v^{(s 1)}(x, y, z)=v_{0}(x, y)+\frac{h_{c}}{2} \beta_{x}^{(c)}+\frac{h_{s}}{2} \beta_{x}^{(s 1)}-z^{(\mathrm{s} 1)} \beta_{x}^{(s 1)} \\
w^{(s 1)}(x, y, z)=w_{0}(x, y)
\end{array}\right. \\
& \left\{\begin{array}{l}
u^{(s 2)}(x, y, z)=u_{0}(x, y)+\frac{h_{c}}{2} \beta_{y}^{(c)}+\frac{h_{s}}{2} \beta_{y}^{(s 2)}+z^{(\mathrm{s} 2)} \beta_{y}^{(s 2)} \\
v^{(s 2)}(x, y, z)=v_{0}(x, y)-\frac{h_{c}}{2} \beta_{x}^{(c)}-\frac{h_{s}}{2} \beta_{x}^{(s 2)}-z^{(\mathrm{s} 2)} \beta_{x}^{(s 2)} \\
w^{(s 2)}(x, y, z)=w_{0}(x, y)
\end{array}\right.
\end{aligned}
$$

The weak-form of the equilibrium equations for sandwich folded plates can be written as in [4].

$$
\int_{\Omega} \sum_{k=1}^{3} \delta \boldsymbol{\varepsilon}^{(k)^{T}} \mathbf{Q}^{(k)} \boldsymbol{\varepsilon}^{(k)} \mathrm{d} \Omega+\int_{\Omega} \sum_{k=1}^{3}\left(\delta \mathbf{u}^{(k)}\right)^{T} \mathbf{m}^{(k)} \ddot{\mathbf{u}}^{(k)} \mathrm{d} \Omega=\int_{\Omega} \delta \mathbf{u}^{T} \mathbf{b} \mathrm{d} \Omega
$$

where $k$ denotes skin layers $(s 1, s 2)$ and core layer $(c)$; $\mathrm{b}$ is the distributed load applied on the plate; $\mathrm{u}$ is the generalized displacement vector; $\mathbf{Q}^{(k)}$ are matrices of material constants; $\boldsymbol{\varepsilon}^{(k)}$ are strain vectors that directly compute form Eq. (1)-(3); and $\mathrm{m}^{(k)}$ are mass matrices [10].

\section{FORMULATION OF CS-DSG3 METHOD USING} LW THEORY FOR SANDWICH FOLDED PLATE

CS-DSG3 using triangular elements have been proposed for static, free vibration and dynamic analysis of plate and shell. In this method, the bounded domain
$\Omega$ is disjointed into $N_{e}$ non-overlapping triangular elements $\left(\Omega=\bigcup_{e=1}^{N_{e}} \Omega_{e}\right.$ ). Each $\Omega_{e}$ triangular element is divided into three sub-triangles $\Delta_{i}, i=1,2,3$, then in each sub-triangle, the DSG3 is used to compute the strain field. Finally the strains smoothing technique is used on the whole triangular element to smooth the strains. Details of the formulation of the CS-DSG3 can be found in [9]. After applying the above process, an equation of static and free vibration analysis for laminate folded composite plate in global coordinate is obtained, respectively.

\section{Trang 216}




$$
\begin{gathered}
{\left[\mathbf{T}^{T} \tilde{\mathbf{K}}^{e} \mathbf{T}\right] \mathbf{d}=\mathbf{T}^{T} \mathbf{F}^{e}} \\
{\left[\mathbf{T}^{T} \mathbf{M}^{e} \mathbf{T}\right] \ddot{\mathbf{d}}+\left[\mathbf{T}^{T} \tilde{\mathbf{K}}^{e} \mathbf{T}\right] \mathbf{d}=0}
\end{gathered}
$$

where, $\mathrm{T}$ is the transformation matrix that is transformed from local coordinate to global coordinate and is presented in [14]. $\tilde{\mathbf{K}}^{e}$ is smoothed element stiffness matrix; $\mathbf{M}^{e}$ is mass matric defined by lump mass technique [5]; and $\mathrm{F}^{e}$ is load vector.

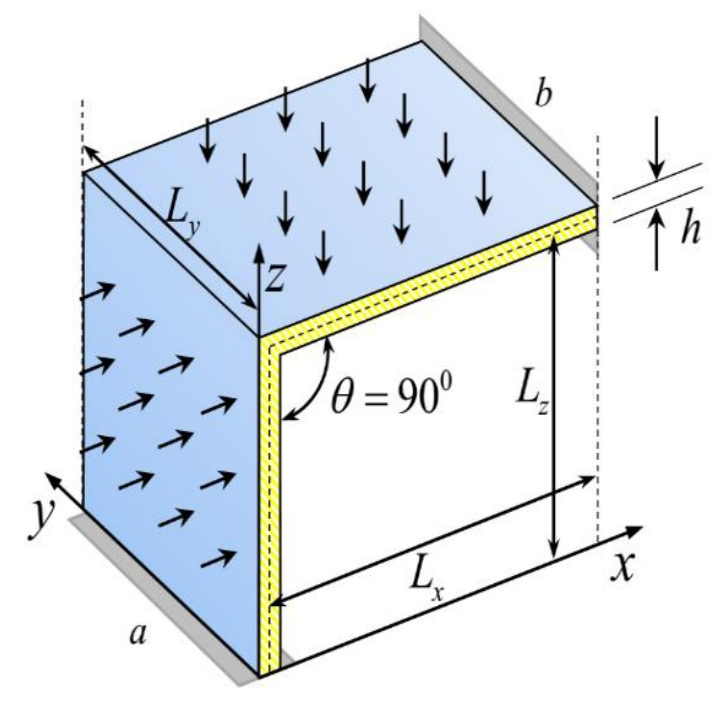

\section{NUMERICAL RESULTS}

Table 1. It is obvious that, steel is significant harder and heavier than PU and the thickness of skin layers is significant thinner than core layer. So the mechanical behavior of this structure is complex.

Table 1. Mechanical properties of steel and polyurethane foam

\begin{tabular}{lccc}
\hline & & Steel & PU \\
\hline $\begin{array}{l}\text { Mass } \\
\left(\mathrm{kg} / \mathrm{m}^{3)}\right.\end{array}$ & density & 7850 & 25.6 \\
$\begin{array}{l}\text { Young's } \\
(\mathrm{Pa})\end{array}$ & modulus & $E=2 \times 10^{11}$ & $E=2.78 \times 10^{6}$ \\
$\begin{array}{l}\text { Shear's modulus } \\
(\mathrm{Pa})\end{array}$ & $G=7.69 \times 10^{10}$ & $G=9.59 \times 10^{5}$ \\
\begin{tabular}{l} 
Poisson's ratio \\
\hline
\end{tabular}
\end{tabular}

Static analysis of a sandwich folded plate

First, the static analysis of folded plate is investigated. The folded plate is clamped at the sides a and $\mathrm{b}$ and subjected to uniformly distributed load ( $\mathrm{P}=10$ $\mathrm{KPa}$ ). The central deflections ( $\mathrm{mm}$ ) of plates and the shapes of deformation using present element are presented in comparison with those solved by EQ theory and commercial program ANSYS as shown in Table 2 and Fig. 3.

Fig. 2. One-fold folded plate clamped at two edges a and b

Table 2. The central deflection ( $\mathrm{mm}$ ) of one-fold folded plate

\begin{tabular}{cccccccc}
\hline \multirow{2}{*}{ Theory } & \multicolumn{5}{c}{ CS-DSG3 - Number of nodes } & ANSYS \\
\cline { 2 - 7 } & $5 \times 5$ & $7 \times 7$ & $9 \times 9$ & $11 \times 11$ & $13 \times 13$ & $25 \times 25$ & 42112 nodes \\
\cline { 2 - 6 } LW & 2.732 & 2.885 & 2.934 & 2.959 & 2.974 & $3.000(27.77 \%)$ & \\
EQ & 0.020 & 0.023 & 0.025 & 0.025 & 0.025 & $0.026(14642 \%)$ & 3.833 \\
\hline
\end{tabular}




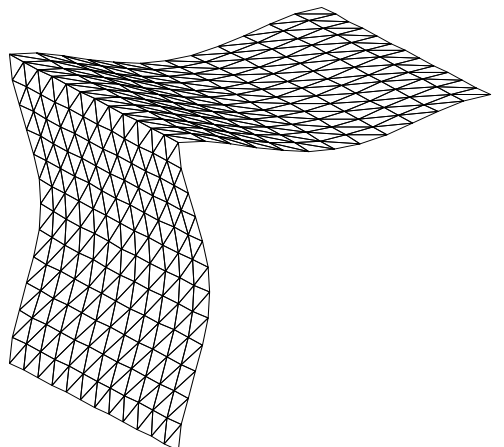

(A)

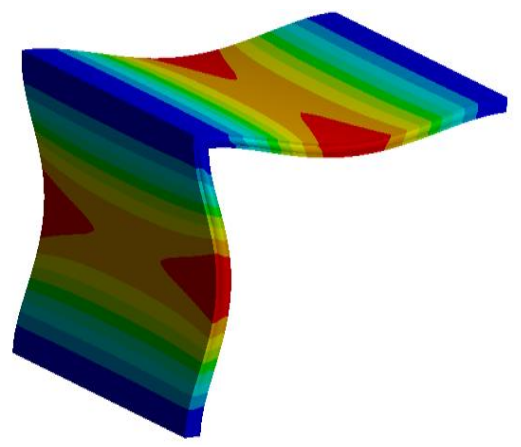

(B)

Fig. 3. Comparison of deformation between (A) CSDSG3 and (B) ANSYS

The commercial ANSYS program uses 18800 hexahedral 3D elements with 125165 nodes. From the Table 2, it can be seen that results Table 2 from EQ theory are poor and unaccepted (error compared to those from ANSYS is $14642 \%$ ). In spite of using the same meshing, results obtained by LW theory are better than those by EQ and can be accepted (error compared to those from ANSYS is $27.7 \%$ ). These results hence illustrate partly the power of LW theory for very complicated problem such as sandwich folded plate.
Free vibration analysis of a sandwich folded plate

In this example, the free vibration analysis of above structure is studied. The frequencies $(\mathrm{Hz})$ of first five modes are shown in Table 3 and in comparison with those from EQ theory and ANSYS software. The first five frequencies and first three mode shapes of the sandwich folded plate are also plotted in Fig 4 and Fig. 5. It can be seen that EQ theory can't be applied for sandwich folded plate while results from LW theory show consistency with ANSYS solutions.

Table 3. Frequencies of the sandwich folded plate

\begin{tabular}{cccc}
\hline \multirow{2}{*}{ Mode } & \multicolumn{3}{c}{ Frequency $(\mathrm{Hz})$} \\
\cline { 2 - 4 } & EQ & LW & ANSYS \\
\hline 1 & 277.91 & 30.34 & 24.76 \\
2 & 366.24 & 36.75 & 32.14 \\
3 & 392.15 & 41.57 & 32.67 \\
4 & 444.53 & 46.82 & 38.81 \\
5 & 540.37 & 72.15 & 57.51 \\
\hline
\end{tabular}

\section{Trang 218}




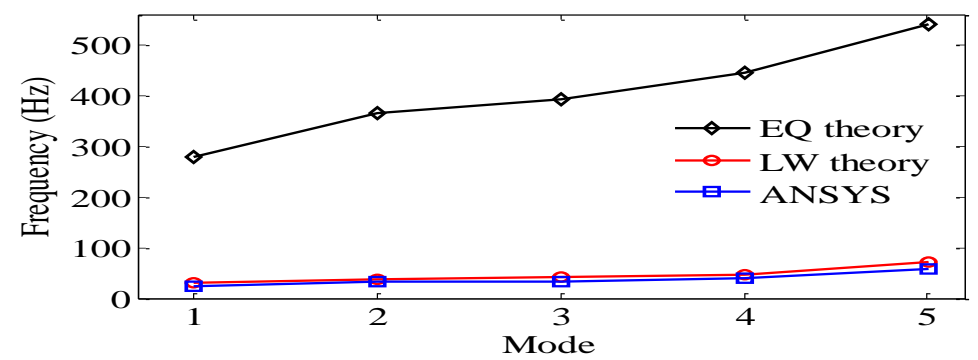

Fig. 4. Comparison of the first five resonance frequencies of a sandwich folded plate

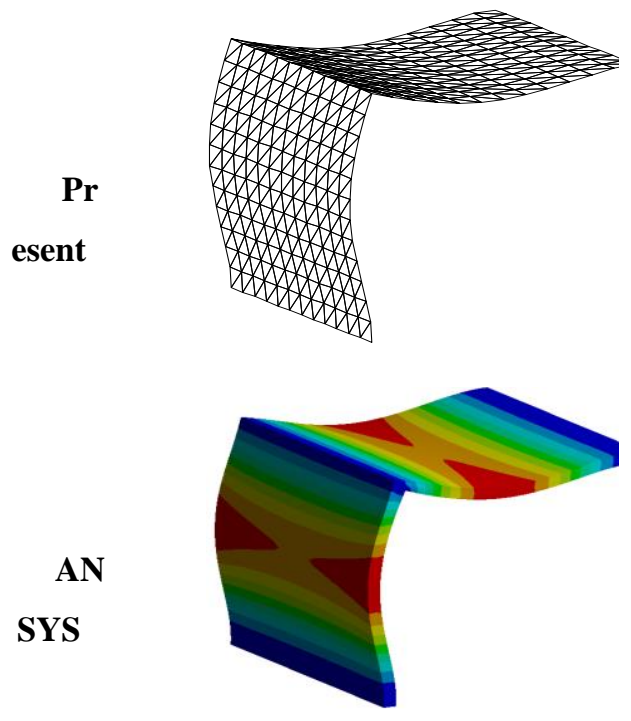

Mode 1
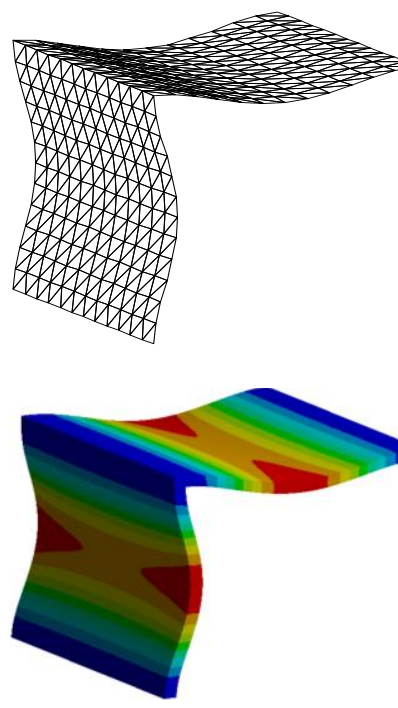

Mode 2
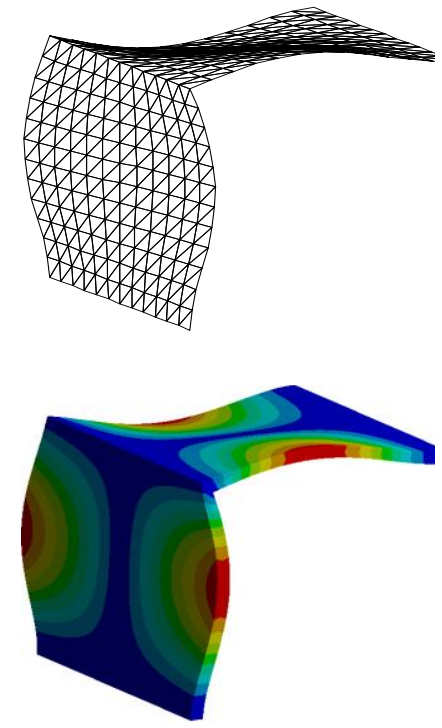

Mode 3

Fig. 5. Comparison of mode shapes between present method and ANSYS model

In the above examples, the differences of performance between EQ and LW compared with ANSYS software. Because material's properties of core and skin layers are significanthy different, EQ theory isn't suitable for this problem. The combination LW and FSDT give better results, however the numerical errors are still large. The cause is the core layer is too thick and soft, so FSDT is not really suitable. A combination LW and high-order deformation theory should be performed in the future.

\section{CONCLUSION}

This paper presented the formulation of sandwich folded plate using layer-wise (LW) theory. In this theory, the behavior of each layer follows the first-order deformation theory (FSDT) and the condition of displacement continuity is imposed at the interfaces of 
layers. Moreover, the equivalent-single layer (EQ) theory and ANSYS software were also used to simulate the response of sandwich folded plates. Through the present formulation and numerical results, $\mathrm{LW}$ is a powerful theory that can be applied for the complex behavior of sandwich folded plate.

Acknowledgements: This research is funded by University of Science, VNU-HCM under Grant No. T2015-01.

\section{Phân tích tĩnh học và dao động tự do của tấm gấp composite nhiều lớp sử dụng lý thuyết tách lớp}

- Bùi Xuân Thắng

Trường Đại học Khoa học Tự nhiên, ĐHQG-HCM

- Đặng Trung Hậu

Viện Khoa học tính toán, ĐH Tôn Đức Thắng

\section{TÓM TẮT}

Trong báo cáo này, chúng tôi phân tích tĩnh học và dao động tư do của tấm gấp composite nhiều lớp bằng mô hình lý thuyết tách lớp (LWT). Trong lý thuyết này, điều kiện liên tục của chuyển vị được sủ dụng tại mặt tách giũa các lớp. Giả thiết biến dạng cắt bậc nhất

(FSDT) được sủ dụng để mô hình mỗi lớp của tấm. Lời giải số của bài toán được tìm bằng phuong pháp phần tử hưu hạn làm trơn CS-DSG3. Các thí du số đurợc thực hiện để mô tả sự chính xác của LWT cho các phân tích tấm gấp composite nhiều lớp.

Tù khóa: tấm gấp composite nhiều lớp, lý thuyết tách lóp, phuơng pháp trơn hóa phần tử rời rạc độ lệch truoơt (CS-DSG3)

\section{REFERENCES}

[1]. L.L. Anh, T.N. Thoi, V.H. Huu, H.D. Trung, T.B. Xuan, Static and frequency optimization of folded laminated composite plates using an adjusted differential evolution algorithm and a smoothed triangular plate element, Composite Structures, 127, 382-394 (2015).

[2]. J.E. Goldberg, H.L. Leve, Theory of prismatic folded plate structures, Int Ass Bridge and Structural Engineering, 17, 59-86 (1957).

[3]. P.B. Yoseph, I. Hersckovitz, Analysis of folded plate structures, Thin-Walled Structures, 7, 139-158 (1989).
[4]. L.X. Peng, S. Kitipornchai, K.M. Liew, Bending analysis of folded plates by the FSDT meshless method, Thin-Walled Structures, 44, 1138-1160 (2006).

[5]. N.N. Minh, T.N. Thoi, T.B. Xuan, T.V. Duy, Static and free vibration analyses of stiffened folded plates using a cell-based smoothed discrete shear gap method (CS-FEM-DSG3), Applied Mathematics and Computation, 266 212-234 (2015) .

[6]. A.G. Niyogi, M. Laha, K, P. Sinha, K, Finite element vibration analysis of laminated composite

Trang 220 
folded plate structures, Shock and Vibration, 6, 273-283 (1999).

[7]. S. Haldar, A.H. Sheikh, Free vibration analysis of isotropic and composite folded plates using a shear flexible element, Finite Elements in Analysis and Design, 42, 208-226 (2005).

[8]. L.X. Peng, K.M. Liew, S. Kitipornchai, Bending analysis of folded laminated plates by the fsdt meshfree method, Procedia Engineering, 14, 27142721 (2011).

[9]. T.N. Thoi, P.P. Van, H.N. Xuan, C.T. Hoang, A cell-based smoothed discrete shear gap method using triangular elements for static and free vibration analyses of Reissner-Mindlin plates, International Journal for Numerical Methods in Engineering, 91, 705-741 (2012).

[10]. P.P. Van, T.N. Thoi, H.D. Trung, N.N. Minh, A cell-based smoothed discrete shear gap method (CSFEM-DSG3) using layerwise theory based on the $\mathrm{C}$ 0-HSDT for analyses of composite plates, Composite Structures, 111, 553-565 (2014).

[11]. T.N.Thoi, P.P. Van, C.T. Hoang, H.N.Xuan, A cellbased smoothed discrete shear gap method (CSDSG3) using triangular elements for static and free vibration analyses of shell structures, International Journal of Mechanical Sciences, 74, 32-45 (2013).
[12]. P.P. Van, T.N. Thoi, T.L. Dinh, H.N. Xuan, Static and free vibration analyses and dynamic control of composite plates integrated with piezoelectric sensors and actuators by the cell-based smoothed discrete shear gap method (CS-FEM-DSG3), Smart Materials and Structures, 22, 095026 (2013).

[13]. H.D. Trung, H.L. Van, T.N. Thoi, K. Ang, Analyses of stiffened plates resting on viscoelastic foundation subjected to a moving load by a cell-based smoothed triangular plate element, International Journal of Structural Stability and Dynamics, 1750011 (2016).

[14]. K. Kansara, Development of Membrane, Plate and Flat Shell Elements in Java. Master of science, Virginia Polytechnic Institute and State University (2004).

[15]. C.A. Shankara, N.G.R. Iyengar, A C0 element for the free vibration analysis of laminated composite plates, Journal of Sound and Vibration, 191,721738 (1996). 